\title{
Bulbus Cordis
}

National Cancer Institute

\section{Source}

National Cancer Institute. Bulbus Cordis. NCI Thesaurus. Code C34114.

A chamber of the embryonic heart that develops into the right ventricle and the outflow tract of both ventricles. 